\title{
Forests in Relation to Stream-flow and Erosion.
}

O $\mathrm{NE}$ of the common marvels to the ordinary person is that so little is really known about such an everyday phenomenon as rainfall. It is a satisfaction to remember that, thanks to the British Rainfall Organization, more is known of the rainfall of Britain than of any other country, but our complacency may be a little disturbed when we reflect that for investigations as to what happens to the rain after it falls we have to turn to other lands. Water-engineers, indeed, have data from which much might be learned; but water engineers are secretive folk, and the records of investigations on the run-off of the Severn, Exe, and Medway remain the only records generally accessible. The results of these investigations, though extremely valuable, are not, however, very definite, as the areas are so large and the problems correspondingly complicated. More definite results are to be expected from the experiment being carried out by the United States Department of Agriculture in Colorado. ${ }^{1}$ The areas dealt with are small and the problem more defined, though even in the small areas there studied conditions are by no means so simple as might be desired.

The intention of the experiment planned in I909 was to make a complete study of the effects of forest cover on stream-flow and erosion. The main idea of the method employed is simple enough. It was, to select two small forest-covered valleys, contiguous, of the same size, similar and similarly situated, to find the rainfall and run-off from each, then cut down the forest from one of the areas and repeat observations. It appears almost a laboratory experiment. The first trouble was the trouble of the cook who desires to cook a hare, or perhaps it would be better to say, a brace of grouse, and it must be confessed at once that though two somewhat similar birds were caught they were not of the same kind, and as investigation proceeded unexpected anatomical differences presented themselves, extremely interesting in their own way, but not making for uniform cooking; it appears also that even if they had been both of a kind they were particularly difficult birds to cook. The valleys chosen lie about the ro, , o feet level in a region with precipitation about 20 inches a year, about half of which falls as snow and a goodly proportion of the rain in thunderstorms, both phenomena introducing difficulties.

The publication before us is a preliminary report giving an account of the first part of the experiment from IgI I to I9I9, and discusses the data obtained while both valleys, $\mathrm{A}$ and $\mathrm{B}$, were forest covered. Both valleys are small, $B$ of 200 acres and A a little larger, varying in elevation from just over 9000 feet to just under $\mathrm{II}, 000$ in the case of $\mathrm{B}$, and somewhat over in the case of A. The geological structure is identical, namely, augite-quartz-latite, little porous to water, covered with a few feet of soil and decomposed rock, porous and sandy in texture, forming a permeable and well-drained top layer. The forest cover, conifers of various kinds, is almost identical. The valleys are not, however, of quite the same shape-A is long and narrow, $\mathrm{B}$ is much more like a bowl; the exposure is rather

I "Stream-flow Experiment at Wagon Wheel Gap, Colorado," Monthly Weather Bureau Supplement, No. r7. Government Printing Office, Washington, 1922.

NO. 2735 , VOL. IO9] different, the centre line of A being south of east, while that of $B$ is north of east. This is important in view of the fact that the winter snowfall runs off as it is melted by the summer sun, and indeed both the time and degree of response of the two streams to any factor influencing the régime are somewhat dissimilar. For example, after rainfall $A$ rises more rapidly and reaches its maximum flow earlier than $\mathrm{B}, \mathrm{B}$ may then be higher than A for a time, while at the end of the flood A may be higher than B. As a result, it has been necessary to construct tables and diagrams to show the relation of $\mathrm{B} / \mathrm{A}$ for a great variety of conditions, and some 16 "rules" have been formulated for comparing the discharge of $\mathrm{B}$ when the discharge of $\mathrm{A}$ and the rainfall is known.

The readings for the run-off may probably be accepted. Very great care has been taken to construct suitable dams, gauges, and basins. The construction of the measuring apparatus is described in great detail, and the readings appear in general to have been exceedingly accurate and trustworthy. But it is a little difficult to place implicit confidence in either the precipitation statistics or the use that is made of them. Though details are, perhaps significantly, lacking, it is evident that the exposure of the gauges for rain and snow is not up to the standard required in this country, while their distribution also leaves something to be desired. Only five were set up in the two valleys; two are close together in the lower part of each basin and one at almost the highest point of $A$, while a sixth was just outside the lower portion of both basins.

The number would, of course, be abundant for ordinary rainfall work, but in a scientific experiment which is otherwise marked by accuracy, British experience would suggest that the number was inadequate, and we should imagine that over a vertical height of 2000 feet there would be considerable differences in rainfall, especially when a good proportion of the rain falls in thunderstorms. It is possible that conditions are different in Colorado, but we should have been more satisfied if evidence had been adduced to show that this was so. Nor is our confidence increased when we learn that in the second part of the experiment, when the forest is removed from $B$, only the gauges in the $A$ valley are to be read. It is scarcely sufficient to say that " the use of the single record cannot be seriously objected to when it is considered that at the lower end of $\mathrm{A}$ there is the choice of the better catch of two gauges, and this value is averaged with the catch of the third gauge at the head of the valley." The italics are ours. It is only fair to say that much more care has been taken with another and equally important side of the problem, the melting of the snow. Observations of the depth of the snow at the time of thaw are taken at a considerable number of points.

It will be interesting to see in ten years' time the results of removing the forest. No doubt valuable results will be obtained which will be of use in dealing with the Forest Reservations of the Rockies, but even so, light will be thrown on only a small portion of the small problem. We shall know what is the effect of removing forest cover only under somewhat special conditions. There will be plenty room for further investigation. 